\title{
Resenha Neo-hegemonia Americana ou Multipolaridade? Pólos de Poder e Sistema Internacional*
}

\section{Paulo Vizentini e Marianne Wiesebron (orgs). Porto Alegre,} Ed. UFRGS, 2006, 240 páginas.

\section{Cristina Soreanu Pecequilo**}

Wa última década, em especial neste início de século XXI, o processo de transição do equilíbrio de poder iniciado em 1989 caracteriza-se por uma série de oscilações que revelam as contradições associadas à reconfiguração da ordem mundial. Neste momento de incerteza, os Estados buscam reajustar prioridades estratégicas, visando seu reposicionamento nesta ordem, sendo simultaneamente confrontados por vulnerabilidades domésticas. O mesmo dilema é enfrentado pela potência hegemônica, os EUA, que também atravessam um ciclo de mudança em suas doutrinas externas e em seus paradigmas socioculturais internos.

\footnotetext{
* Resenha recebida em dezembro de 2006 e aprovada para publicação em janeiro de 2007.

**Doutora em Ciências Políticas pela Universidade de São Paulo (USP), professora pela Universidade Estadual Paulista (Unesp), pesquisadora associada do Núcleo de Estratégia e Relações Internacionais da Universidade Federal do Rio Grande do Sul (Nerint/UFRGS) e colaboradora da Rede Brasileira de Relações Internacionais da Universidade de Brasília (Relnet /UnB).
}

CONTEXTO INTERNACIONAL Rio de Janeiro, vol. 29, nº 1, janeiro/junho 2007, p. 187-194. 
Diante desse contexto, é essencial que existam análises que cubram a complexidade dessas diferentes dinâmicas como o livro Neo-hegemonia americana ou multipolaridade? Pólos de poder e sistema internacional, da Editora da Universidade Federal do Rio Grande do Sul (UFRGS), organizado por Paulo Vizentini e Marianne Wiesebron. Pertencente à Série Estudos Internacionais, fruto da colaboração entre a Editora da UFRGS e o Núcleo de Estratégia e Relações Internacionais/Instituto Latino-americano de Estudos Avançados (Nerint/ILEA) da mesma Universidade, o livro reforça a tradição da UFRGS no lançamento de obras relevantes no campo das Relações Internacionais, já presente nesta mesma série e na Coleção Relações Internacionais e Integração.

Composto por uma coletânea de artigos, originados a partir de papers apresentados em seminário realizado pelo Instituto Clingendale de Relações Internacionais de Haia, o livro simboliza um abrangente esforço de colaboração internacional, reunindo especialistas das mais diversas instituições e origens, como Immanuel Wallerstein e Paul Marie de La Gorce (in memorian). Igualmente, o volume conta com contribuições de Kurt Radtke, Alexander Zhebit, André Gerrits, John Harriss, Paulo Vizentini e Greg Mills.

Estes especialistas, discutindo o futuro do sistema, procuram oferecer estudos específicos dos Estados que se relacionam e/ou se confrontam nessa fase de transição, buscando responder à pergunta-título do livro. Podemos identificar três blocos de reflexão que se complementam e interligam: EUA, Europa/Japão e emergentes, compostos por China, Rússia, Brasil, Índia e África do Sul.

Abrindo estes blocos, o artigo "A doutrina Bush: um ensaio interpretativo", de Immanuel Wallerstein, avalia a evolução das diretrizes estratégicas norte-americanas desde 1945, passando pelo fim da bipolaridade, e chegando até a ascensão neoconservadora do pós-Guerra Fria, culminando na elaboração da doutrina Bush de caráter preventi- 


\section{Resenha}

vo. São avaliados os impactos do 11 de setembro de 2001 para a consolidação dessa estratégia e sua primeira aplicação concreta na Guerra do Iraque e seu encaminhamento entre 2002 e 2003.

Esses acontecimentos, associados à transformação da agenda norte-americana, são percebidos como prova de declínio dos EUA. Para Wallerstein, os neoconservadores, na busca da sua "neo-hegemonia", colocam em questão o futuro da própria dominação. Todavia, esse refluxo não é acompanhado por uma posição concreta de outros atores que poderiam desempenhar um papel mais relevante no cenário, como a União Européia.

Avançando essas discussões, Paul Marie de La Gorce em "A união européia face à unipolaridade e à multipolaridade" aborda especificamente a posição da Europa com relação à doutrina Bush. Indagando sobre a eventual possibilidade de a Europa, como bloco ou individualmente, assumir a responsabilidade de conduzir a ordem mundial, a análise é reticente. Embora de La Gorce reconheça que, positivamente, França e Alemanha tenham desenvolvido uma postura mais autônoma perante os EUA no caso do Iraque, os resultados mantiveram-se limitados a esta situação. O autor, inclusive, relembra brevemente iniciativas independentes de política externa já empreendidas, como o gaullismo, para demonstrar as dificuldades e descontinuidades da relação Europa/EUA e da busca de uma maior autonomia internacional.

Tanto as nações européias como as asiáticas, assim como os Estados emergentes, compartilham situação similar: muitas vezes desejam oferecer caminhos independentes aos da hegemonia norte-americana, mas, simultaneamente, dela dependem em dimensões político-estratégicas e econômicas. Estas nações e/ou blocos possuem vulnerabilidades domésticas que limitam sua projeção, havendo a permanência de desconfianças em relação a possíveis alternativas aos EUA, preferindo-se a manutenção do status quo. Estas situações 
são sentidas mais profundamente nos emergentes (e mesmo no Japão). Modificações graduais, contudo, surgiram no período recente em virtude das posturas neoconservadoras da Presidência Bush que minaram a legitimidade dos EUA diante dos seus aliados e nas organizações internacionais.

Abordando essa encruzilhada do ponto de vista do Japão e da China, Kurt Radtke oferecerá em seu artigo, "Leste Asiático em busca de segurança geopolítica (energética): conceitualização japonesa e chinesa em um mundo em globalização", uma análise bastante complexa da estratégia dessas duas nações. Radtke demonstra de que forma os dois países pensam a questão da segurança no pós-Guerra Fria, focando em suas dimensões globais e intra-asiáticas, somada à relação bilateral com os EUA.

Mesmo que de maneiras diferentes, China e Japão passam por um repensar dessas posturas, que indica a intenção de buscar caminhos mais autônomos, ainda que permaneçam dependentes dos EUA em certos setores. Cinco prioridades de segurança são identificadas: o acesso a recursos energéticos (a securitização da questão energética, nas palavras do autor); a garantia de mercados; a consolidação das identidades nacionais e a estabilidade interna; a transformação rápida da configuração estratégica regional (que inclui o entorno asiático, a Rússia e o Oriente Médio); e as tendências de ordenamento global que oscilam entre a uni e a multipolaridade.

Ainda que já abordada no artigo de Radtke, a partir da análise da posição chinesa, a defesa de uma ordem multipolar contraposta às vulnerabilidades dos países que a defendem será um dos elementos centrais dos artigos do terceiro bloco. Tais artigos terão como foco o estudo da postura externa e de segurança dos países emergentes, em busca de maior autonomia e de um reposicionamento internacional em suas relações estatais e nos organismos multilaterais. 
O debate inicia-se com dois artigos sobre a Rússia. Escritos por Alexander Zhebit e André Gerrits, respectivamente intitulados "Repensar a Rússia: uma proposta sobre o reposicionamento da Rússia nas relações internacionais" e "Hegemonia americana e multipolaridade: o sistema internacional no século XXI", os textos abordam a trajetória russa de superpotência na era soviética à nação emergente, pertencente ao grupo denominado BRIC (Brasil, Rússia, Índia e China).

Zhebit e Gerrits analisam a quebra da URSS e o começo de sua transição nas fases Gorbachev/Yeltsin, priorizando as estratégias de $\mathrm{Pu}$ tin. Na visão dos autores, a ascensão de Putin ao poder representou uma inflexão geopolítica, revertendo o quadro de inexorável declínio que parecia ter se estabelecido. Na busca da recuperação doméstica, Putin desenvolveu iniciativas direcionadas a diminuir a crise socioeconômica, tentando recuperar o Estado. No campo externo, o desenvolvimento de uma política externa pragmática ganhou destaque.

Tal pragmatismo se revela no equilíbrio das fragilidades e potencialidades russas, mantendo uma relação produtiva, mas não subordinada, com o Ocidente, a União Européia e os EUA (e também cautelosa, como no caso da expansão da Organização do Tratado do Atlântico Norte (OTAN)). Apesar do desaparecimento do status de superpotência, da realidade de um mundo unipolar e dos pontos de estrangulamento referentes à economia, sistema político/democracia e modernização tecnológica, a Rússia preservou vantagens comparativas em termos de recursos de poder: "armas, energia e geografia", como menciona Gerrits na página 196.

Tais recursos permitem que a Rússia, mesmo sendo definida por Gerrits como uma potência de segunda ordem (p. 178), preserve relativa autonomia no sistema. Essa inserção mediada pode ser percebida pelo fato de que o país, em nenhum momento, abandonou seus interesses em seu entorno (a região correspondente ao antigo império soviético na Ásia Central); suas parcerias no Oriente, destacando-se o 
intercâmbio com a China; a atenção aos demais Estados emergentes como o Brasil; e sua atuação na Organização das Nações Unidas (ONU), pleiteando maior relevância no G8 e sua entrada na Organização Mundial do Comércio (OMC). Mesmo assim, os autores concordam que essa ação de baixo perfil é acompanhada pela vocação natural russa de potência, existindo o risco de agendas revisionistas.

Continuando na análise dos emergentes, o texto de John Harriss, "Índia: os amargos frutos da ambição grandiosa", aborda a trajetória da Índia do Movimento Não-Alinhado (MNA) até o pós-Guerra Fria, apresentando uma perspectiva também da evolução da política interna e externa deste país. Bastante crítica, a avaliação de Harriss é de que a Índia, em busca da autonomia via nuclearização para contrapor-se ao Paquistão e à China, gerou uma situação de maior dependência perante os EUA. Em termos de relações internacionais, Harris identifica essa tendência, na passagem da autonomia do MNA dos anos 1960 à ambiguidade das décadas de 1970/1980, à reaproximação recente com os norte-americanos. Tal reaproximação é vista como uma limitação estratégica, assim como a compreensão parcial das mudanças regionais pós-11 de setembro, dos impactos da guerra contra o terrorismo e da não-resolução das dificuldades internas. Todavia, a Índia não abandonou suas parcerias com os Estados emergentes, como destacado na contribuição seguinte de Paulo Vizentini.

Um dos organizadores do livro, Vizentini, que também escreve a Introdução do mesmo (sendo a coletânea prefaciada por Wiesebron), contribui com o artigo "O Brasil e a integração sul-americana: força e fragilidade de um gigante periférico". O autor examina os dilemas do reordenamento do ponto de vista da diplomacia brasileira, atentando para as preocupações de segurança nacional (questão amazônica, riscos transnacionais, tríplice fronteira, vulnerabilidades socioeconômicas). Soberania e não-intervenção são temas igualmente analisados, relacionando-os às pressões exercidas pelos países desenvolvi- 
dos para a adesão às agendas do neoliberalismo e a regimes internacionais.

Os impactos dessas políticas são abordados, avaliando as respostas mais recentes a esses desafios, tendo como preocupação central a integração regional sul-americana, iniciada com a Cúpula de Brasília de Fernando Henrique Cardoso, até as ações da Presidência Lula no âmbito Sul-Sul, nas organizações internacionais e para a recuperação do Estado.

Fechando o livro, Greg Mills analisa, em "Pólos à parte? África do Sul, Iraque e o debate unilateralismo-multipolaridade", o direcionamento e agenda de política externa da África do Sul. Mills oferece uma crítica à política dos EUA com relação ao Iraque, examinando os impactos do unilateralismo para a reconfiguração do sistema e para os Estados emergentes. Além disso, o autor define as cinco prioridades estratégicas-chave da política externa da África do Sul, que revelam sua preocupação tanto com a projeção externa do país como com a administração de seus pontos de estrangulamento internos (direitos humanos, economia, melhoria do Estado, a construção de uma África e de um mundo melhor são os elementos listados na página 229).

Diversificado em suas contribuições, o livro Neo-hegemonia americana ou multipolaridade? Pólos de poder e sistema internacional é, portanto, uma relevante fonte de estudos para a área de Relações Internacionais no país, na medida em que fornece um panorama crítico-analítico do atual processo de reconfiguração do sistema internacional. Como bem destaca Radtke: "Discussões sobre polaridade refletem, mas ao mesmo tempo afetam profundamente as identidades de segurança dos países" (p. 69) "conceitos de segurança não operam no vácuo" (p. 138).

Ao preencher esse "vácuo", o livro traz ao leitor brasileiro uma série de debates que são pouco conhecidos sobre Estados como Rússia, 
Índia, China e África do Sul, que hoje são o foco da política externa. Estamos diante de um cenário em construção de neo-hegemonia, de multipolaridade, de escolhas e decisões estratégicas, que, no médio ou longo prazo, consolidará o novo perfil do sistema. E, para agir nesse mundo, é fundamental que conheçamos não só nossos próprios limites e potencialidades, mas também os de nossos parceiros, tanto ao Norte quanto ao Sul. 